\title{
KRITERIA PEMILIHAN MATERIAL SOFTSCAPE DAN HARDSCAPE LANSKAP BERKELANJUTAN UNTUK RANCANGAN TAMAN MERAH KAMPUNG PELANGI KOTA MALANG
}

\author{
Hamka \\ Dosen Prodi Arsitektur, Fak. Teknik Sipil dan Perencanaan, ITN Malang \\ e-mail: hamka07@lecturer.itn.ac.id \\ Suryo Tri Harjanto \\ Dosen Prodi Arsitektur, Fak. Teknik Sipil dan Perencanaan, ITN Malang \\ e-mail: totosuryo@lecturer.itn.ac.id \\ Adhi Widyarthara \\ Dosen Prodi Arsitektur, Fak. Teknik Sipil dan Perencanaan, ITN Malang \\ e-mail: adhiwidyarthara@gmail.com
}

\begin{abstract}
ABSTRAK
Taman Merah Kampung Pelangi rancangannya direncakan dengan menggunakan konsep lanskap berkelanjutan, yaitu memepertimbangkan aspek lingkungan, sosial budaya, ekonomi, estetika dan institusional. Namun untuk memenuhi aspek lingkungan dan estetika maka perlu dilakukan kajian kriteria material softscape dan hardscape lanskap yang memiliki dampak positif terhadap lingkungan dan juga estetik secara visual. Tujuan dari penelitian ini adalah untuk mengidentifikasi ketepatan pemilihan material softscape dan hardscape yang sesuai dengan konsep rancangan. Metode yang digunakan adalah metode analisis deskriptif berdasarkan studi literatur terkait manfaat dari jenis material softscape dan hardscape lanskap. Hasil kajian menunjukkan bahwa material softscape yang digunakan adalah dibagi menjadi tiga yaitu tanaman untuk fungsi ekologi, fungsi estetika dan fungsi ekonomi atau ketahanan pangan berupa tanaman produktif. Material hardscape diselesaikan dengan cara mengurangi penggunaan perkerasan secara keseluruhan, misalkan kombinasi antara beton dan rumput, krikil atau batu koral, penggunaan pasir putih untuk lapangan futsal dan volley. Hal tersebut bertujuan agar area resapan air pada taman tetap terjaga.
\end{abstract}

Kata kunci : material lanskap, arsitektur lanskap, ruang terbuka

\begin{abstract}
The design of Taman Merah Kampung Pelangi is planned using the concept of a sustainable landscape, which considers environmental, sociocultural, economic, aesthetic and institutional aspects. However, to fulfill the environmental and aesthetic aspects, it is necessary to study the materialts of landscape softscape and hardscape which have a positive impact on the environment as well as aesthetic visually. The purpose of this study was to identify the appropriate selection of softscape and hardscape materialts in accordance with the design concept. The method
\end{abstract}


used is descriptive analysis method based on literature studies related to the benefits of the types of materialts of landscape softscape and hardscape. The results of the study indicate that the softscape materialts used are divided into three, namely plants for ecological functions, aesthetic functions and economic functions or food security in the form of productive plants. Hardscape materialts are resolved by reducing the use of pavement as a whole, for example a combination of concrete and grass, gravel or coral, the use of white sand for futsal and volleyball courts. It is intended that the water catchment area in the park is maintained.

\section{Keywords : landscape materialt, landscape architecture, open space}

\section{PENDAHULUAN}

Kegiatan perancangan ini merupakan bagian dari program pengabdian kepada masyarakat. Taman Merah Kampung Pelangi dirancang untuk memenuhi area ruang terbuka hijau perumahan permukiman dan sebagai ruang komunal warga yang berada diwilayah Kampung Pelangi RW 9 Kelurahan Merjosari Kota Malang. Taman Merah ini didesain untuk mendukung arah pengembangan wisata kampung tematik yang ada di Kota Malang. Untuk mengarah pada pengembangan kampung wisata tersebut maka perlu konsep berkelanjutan yang dapat menggerakkan berbagai aspek kemasyarakatan di Kampung Pelangi. Konsep yang sejalan dengan hal tersebut adalah arsitektur lanskap berkelanjutan. Arsitektur lanskap berkelanjutan adalah arsitektur yang mempertimbangkan lima aspek berkelanjutan yaitu, aspek lingkungan (kualitas udara, air, tumbuhan dan satwa liar), aspek ekonomi berupa hasil pertanian/ budidaya dan pariwisata, sosial budaya meliputi (kesehatan, pendidikan, pengetahuan lokal, partisipasi dan karakter budaya), aspek estetiika (kualitas visual dari ruang dan tempat), dan aspek politik mengenai kebijakan (Çiftçioğlu and Sözen, 2017).

Tujuan dari pada penelitian ini adalah untuk mendukung penerapan aspek arsitektur lanskap berkelanjutan dalam konteks pemilihan jenis material softscape dan hardscape taman. Material softscape dan hardscape yang dipilih harus memiliki fungsi ekologi untuk memperbaiki kualitas lingkungan, fungsi ekonomi yang dapat menghasilkan, fungsi sosial budaya yang dapat memberikan pengetahuan, fungsi estetika yang memberikan pengalaman ruang dan fungsi politik yang memberikan dampak kerjasama bagi warga sekitar. Sehingga perlu identifikasi untuk memilih material softscape dan hardscape yang sesuai dengan konsep berkelanjutan.

Kondisi tapak Taman Merah terlihat masih terdapat berbagai macam material softscape eksisting berupa pepohonan sebagai fungsi peneduh seperti pohon kiara payung, pohon mangga, pohon genitu, tanaman produktif seperti papaya, pisang, dan ubi-ubian serta beberapa tanaman

PAWON: Jurnal Arsitektur, Nomor 01 Volume V, Bulan Januari-Juli Tahun 2021, ISSN 2597-7636 
obat-obatan seperti kunyit, jahe, dan sereh. Selain itu juga terdapat tanaman hias berupa bunga-bunga yang ditanam dalam media pot dan juga beberapa tumbuh liar didalam area lahan Taman Merah, (Gambar 1).
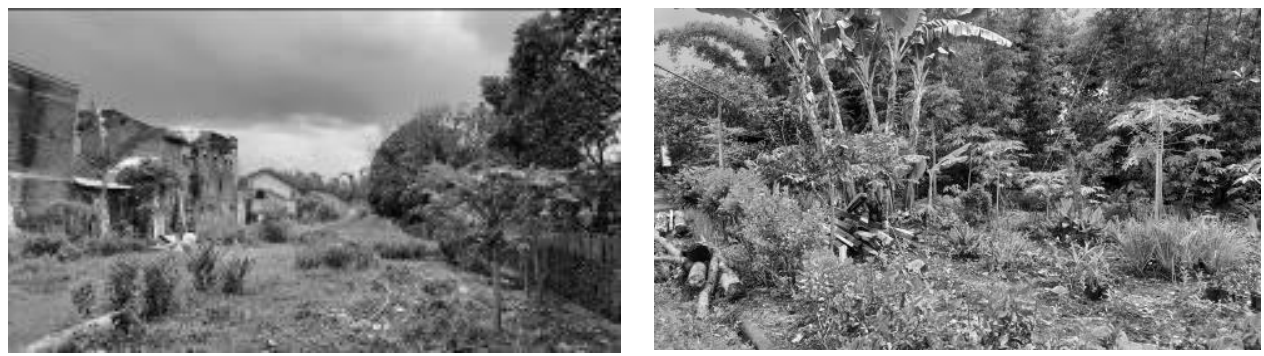

Gambar. 1

Kondisi vegetasi yang terdapat dalam tapak

Sumber: Hasil survei 2020

\section{TINJAUAN PUSTAKA}

\subsection{Arsitektur Lanskap Berkelanjutan}

Lanskap merupakan kondisi fisik bentang alam yang memiliki karakter tertentu yang dapat dilihat dan dirasakan oleh indra manusia, (Simonds, 2006). Arsitektur Lanskap merupakan ilmu yang digunakan untuk merencanakan dan merancang tapak, mengatur penggunaan material alami maupun buatan dengan mempertimbangkan kebutuhan dan aspek pemeliharaan paska bangun agar memberikan hasil yang fungsional namun tetap estetik (Hakim, 2000). Menurut Suharto (dalam Susanti, 2000) lanskap meliputi seluruh komponen tapak, yang terdiri dari material alami (natural landscape) dan material buatan (artificial landscape) serta makhluk hidup yang terdapat di dalamnya. Arsitektur lanskap berkelanjutan dapat dilihat dari beberapa kriteria dan indikator, (Hamka, Winarni, \& Widhyarthara, 2020) (Tabel 1).

Tabel 1.

Kriteria dan indikator arsitektur lanskap berkelanjutan

\begin{tabular}{ll}
\hline Kriteria & Indikator \\
\hline Environmental & $\begin{array}{l}\text { Tersedianya ruang terbuka hijau, menjaga kualitas air dan } \\
\text { udara, flora dan fauna, pemanfaatan lahan menjadi produktif, } \\
\text { penetapan fungsi guna lahan, penggunaan material ramah } \\
\text { lingkungan, hemat energi }\end{array}$ \\
\hline Economic & $\begin{array}{l}\text { Budidaya pertanian dan peternakan, pengembangan wisata, } \\
\text { kewirausahaan/ investasi/ ketenagakerjaan }\end{array}$ \\
\hline Social-culture & $\begin{array}{l}\text { Pendidikan, kesehatan, pengalaman ilmu pengetahuan, } \\
\text { identitas budaya/ kearifan local, ruang interaksi sosial, } \\
\text { kerjasama kelompok atau individu }\end{array}$ \\
\hline Architectural & Memberikan pengalaman ruang dan tempat dari kualitas visual \\
\hline
\end{tabular}

PAWON: Jurnal Arsitektur, Nomor 01 Volume V, Bulan Januari-Juni Tahun 2021, ISSN 2597-7636 


\begin{tabular}{ll}
\hline & yang menarik dan kenyamanan lingkungan \\
\hline Institutional & Kebijakan, partisipasi dan komitmen seluruh pihak
\end{tabular}

Sumber: Hamka, Winarni, \& Widhyarthara, 2020

\subsection{Material Lanskap}

Material lanskap dibagi menjadi 2 bagian utama menurut (Hakim, 2000), yaitu material lunak (soft materials/ softscape) dan materi keras (hard materials/ hardscape). Material lunak yang dimaksud adalah vegetasi/ pepohonan, tanah dan air, sedangkan material keras dikelompokkan dalam 5 jenis kelompok besar yaitu, material keras yang alami seperti kayu, material keras alami dari dalam bumi seperti batu-batuan, material keras buatan bahan dasar metal semisal besi dan baja, material buatan bahan sintetis atau tiruan sperti plastic dan fiberglass, material keras buatan bahan campuran seperti beton dan plywood.

Menurut (Ashihara, 1996) mengenai perancangan sebuah taman perlu adanya penataan dan pemilihan material yang sesuai dengan kondisi lahan, agar rancangan taman dapat fungsional dan estetis. Unsur taman dikelompokkan kedalam 3 jenis, yaitu: (1) jenis dasar (elemen alami/ soft materials seperti air, dan tanaman dan elemen buatan/ hard materials seperti pergola, bangku taman, paving, pagar, patung, bangku, kolam, dan lampu) ; (2) kesan visual yang dihasilkan; dan (3) efek perubahan.

Elemen material lanskap adalah semua hal yang berhubungan dengan lanskap/ taman. Berdasarkan karakternya elemen taman dapat dibedakan menjadi : Material Lunak (soft materials) terdiri dari tanaman dan satwa yang sudah secara alami terdapat di lahan maupun elemen yang secara sengaja diadakan pada lanskap. Material keras (hard materials) meliputi semua elemen lanskap yang memiliki sifat bahan yang padat dan merupakan benda mati diantaranya: tanah, metal, batuan, beton, aspal, jalan setapak, pagar, bangunan, dinding, dan bangunan rumah (Sulistyantara, 2002)

Kegunaan material lunak (softscape) dan material keras (hardscape) menurut (Hakim, 2000), adalah sebagai berikut: Material lunak (softscape) digunakan sebagai: (1) Filter terhadap pandangan (view control), (2) Pembatas fisik (physical barriers), (3) Mengendalikan iklim setempat (climate control), (4) Mencegah terjadinya erosi (erosion control), (5) Tempat tinggal satwa liar (wildlife habitats), (6) Nilai keindahan (aesthetic values). Material keras (hardscape) digunakan sebagai: (1) Memberikan kesan dan karakter ruang dan meningkatkan kualitas visual serta nilai estetika (2) Membangkitkan kreatifitas, inovasi dan jiwa seni seseorang (3) Sebagai wadah untuk mendapatkan perasaan aman dan nyaman (4) Menambah pengetahuan dan wawasan bagi pengunjung atau warga sekitar (5) Sarana rekreasi bagi warga sekitar. 


\subsection{Karakteristik dan kegunaan softscape dan hardscape}

Karakteristik dan kegunaan pohon menurut (Handayani, 2009), sebagai berikut (Tabel 2):

Tabel 2.

Karakteristik dan kegunaan pohon

\begin{tabular}{|c|c|c|}
\hline $\begin{array}{c}\text { Bentuk } \\
\text { tanaman } \\
\text { dan contoh }\end{array}$ & Karakteristik & Kegunaan \\
\hline $\begin{array}{l}\text { Melebar/ } \\
\text { Spreading } \\
\text { (Flamboyan } \\
\text { Sengon } \\
\text { Hujan Mas) } \\
\end{array}$ & $\begin{array}{l}\text { Lebar tajuk kurang lebih sama } \\
\text { dengan tingginya. Memberikan } \\
\text { kesan luas, kontras terhadap } \\
\text { bentuk yang tinggi ramping. }\end{array}$ & $\begin{array}{l}\text { Tepat digunakan } \\
\text { pada permukaan } \\
\text { tanah yang datar. } \\
\text { Untuk menyatukan fungsi } \\
\text { bangunan dengan lahan yang } \\
\text { ada sekelilingnya. }\end{array}$ \\
\hline $\begin{array}{l}\text { Bulat } \\
\text { (Kisabun } \\
\text { Nangka } \\
\text { Kasia } \\
\text { Singapur) }\end{array}$ & $\begin{array}{l}\text { Bentuk ini relative mudah dan } \\
\text { banyak ditemui. Mudah } \\
\text { menyatu dalam suatu } \\
\text { komposisi }\end{array}$ & $\begin{array}{l}\text { Tepat digunakan } \\
\text { pada permukaan } \\
\text { tanah yang datar.Kurang tepat } \\
\text { sebagai pohon pengarah. }\end{array}$ \\
\hline $\begin{array}{l}\text { Ramping dan } \\
\text { tinggi } \\
\text { (Cemara Lilin } \\
\text { Glodongan } \\
\text { Tiang) }\end{array}$ & $\begin{array}{l}\text { Mengarahkan perhatian } \\
\text { pengamat ke } \\
\text { atas. Membentuk ruang dan } \\
\text { dapat menjadi pembeda jika } \\
\text { dikombinasikan dengan bentuk } \\
\text { lain serta } \\
\text { berperan sebagai aksen }\end{array}$ & $\begin{array}{l}\text { Sebaiknya di gunakan pada } \\
\text { area tertentu saja dengan } \\
\text { jumlah yang terbatas. Pohon } \\
\text { ini dapat memecah perhatian } \\
\text { sehingga tidak dianjurkan } \\
\text { secara acak. Berfungsi } \\
\text { sebagai pohon } \\
\text { yang mengarahkan }\end{array}$ \\
\hline $\begin{array}{l}\text { Columnar } \\
\text { (Dammar } \\
\text { Puspa) }\end{array}$ & $\begin{array}{l}\text { Karakternya hamper sama } \\
\text { dengan pohon yang tinggi dan } \\
\text { ramping }\end{array}$ & $\begin{array}{l}\text { Pemanfaatannya sama } \\
\text { dengan pohon yang } \\
\text { berkarakter tinggi ramping }\end{array}$ \\
\hline $\begin{array}{l}\text { Piramidal } \\
\text { (Cengkeh } \\
\text { Cemara } \\
\text { Kipas Pinus) }\end{array}$ & $\begin{array}{l}\text { Bentuk ini mudah dan banyak } \\
\text { ditemui. Sifatnya netral dan } \\
\text { mudah menyatukan dalam } \\
\text { sebuah komposisi bentuk. }\end{array}$ & $\begin{array}{l}\text { Sebagai aksen visual. Tepat } \\
\text { digunakan pada pola-pola } \\
\text { yang geometris }\end{array}$ \\
\hline $\begin{array}{l}\text { Merunduk } \\
\text { (Yang liu } \\
\text { Willow) }\end{array}$ & $\begin{array}{l}\text { Karakter cabangnya } \\
\text { merunduk ke bawah. } \\
\text { Mengarahkan pandangan } \\
\text { pengamat mengarah kebawah }\end{array}$ & $\begin{array}{l}\text { Tepat digunakan pada area } \\
\text { tepian air seperti kolam }\end{array}$ \\
\hline $\begin{array}{l}\text { (Bentuk yang } \\
\text { Menarik) }\end{array}$ & $\begin{array}{l}\text { Karakter unik, menarik dan } \\
\text { eksotis. Bentuknya dapat } \\
\text { berubah secara sengaja oleh } \\
\text { manusia ataupun secara alami } \\
\text { oleh kondisi alam. }\end{array}$ & $\begin{array}{l}\text { Dijadikan sebagai pusat } \\
\text { perhatian dan ditempatkan } \\
\text { pada beberapa area tertentu } \\
\text { saja }\end{array}$ \\
\hline
\end{tabular}

Sumber: Handayani, 2009

PAWON: Jurnal Arsitektur, Nomor 01 Volume V, Bulan Januari-Juni Tahun 2021, ISSN 2597-7636 
Pengelompokan jenis elemen softscape dan hardscape, menurut (Qomarun \& Wahyuni, 2013), yaitu: softscape (1) berdasarkan bentuk tajuk dan struktur tanaman terdiri dari pohon, perdu, semak (shrubs), rambat (liana), dan herbal, (2) berdasarkan pembentuk dan ornamental space terdiri dari tanaman pelantai (Ground cover), tanaman pendinding (dinding rendah, dinding sedang, dinding tinggi, pembatas dan pengarah), tanaman peneduh yang berfungsi sebagai atap, dan tanaman sebagai hiasan dan ornamen ruangan: hardscape terdiri dari batuan, gazebo, bangku taman, kolam dan air, tebing buatan, jalan setapak, perkerasan, lampu taman, pagar, pergola, dan bangunan Gedung.

\subsection{Kriteria Tepat Guna Lahan pada Ruang Terbuka Hijau}

Kriteria tepat guna lahan pada ruang terbuka hijau menurut (Surjana \& Ardiansyah, 2013), adalah sebagai berikut: (1) Proporsi dan skala luasan dan kualitas dari ruang terbuka hijau melalui penanaman pohon yang bervariasi untuk mengurangi emisi dari $\mathrm{CO} 2$, menahan air hujan dan mencegah erosi, serta menjaga habitat satwa liar, (2) Pembangunan kawasan melalui taman pada bagian atap, media pot, vertical garden, dan material keras (hardscape) yang dapat menyerap air, (3) Jalur pencapaian melalui penyediaan jalur pejalan kaki dan pesepeda serta tempat parkirnya, (4) Pertamanan dengan menyediakan area softscape diatas permukaan tanah minimal $40 \%$ dari luas lahan, dan penggunaan tanaman lokal dan budidaya lokal, (5) Kenyamanan iklim mikro dengan perletakan pepohonan pada jalur utama pedestrian untuk melindungi dari radiasi sinar matahari dan angin kencang dan penggunaan material yang memiliki nilai albedo/daya refleksi panas matahari rendah, (6) Manajemen pengelolaan air hujan dengan banyak menggunakan material softscape agar tidak mengurangi area resapan air dan menyediakan penampungan air hujan untuk dimanfaatkan sebagai sumber air.

Kriteria material pelapis permukaan agar mengurangi urban heat island (Pratiwi \& Safitri, 2019), adalah dengan menggunakan material yang memiliki nilai albedo tinggi melalui material-material yang berwarna terang, seperti hijau, dan putih dan abu-abu, hindari material permukaan dari aspal, metal, beton, batu dan tanah liat, gunakan material permukaan dari tanah, rumput atau grass block, manfaatkan pohon untuk memperbanyak area pembayangan.

\section{METODE PENELITIAN}

Metode yang digunakan pada penelitian ini adalah metode kualitatif analisis deskriptif. Data yang dikumpulkan berupa literatur yang membahas tentang material softscape dan hardscape yang sesuai dengan prinsip lanskap berkelanjutan dan ramah lingkungan. Temuan jenis, fungsi dan

PAWON: Jurnal Arsitektur, Nomor 01 Volume V, Bulan Januari-Juli Tahun 2021, ISSN 2597-7636 
karakter material tersebut akan dihubungkan dengan konsep rancangan Taman Merah yang selanjutnya dianalisis berdasarkan kebutuhan dan zonasi fungsi serta kegiatan area taman. Analisis dilakukan untuk memilih material softscape dan hardscape yang ramah lingkungan dan sesuai dengan jenis kegiatan dimasing-masing zonasi taman. Hasilnya berupa daftar material softscape dan hardscape yang akan digunakan pada rancangan Taman Merah.

\section{HASIL DAN PEMBAHASAN}

\subsection{Identifikasi Elemen Lanskap Tapak}

Kondisi eksisting tapak masih berupa lahan kosong yang ditumbuhi tumbuhan secara alami. Pohon eksisitng yang sengaja ditanam berupa pohon kiara payung, pohon mangga dan pohon genitu, pohon bamboo, selebihnya berupa tumbuhan liar seperti rumput dan semak. Warga juga memanfaatkan beberapa area untuk menanam buah-buahan seperti pisang dan papaya, tanaman obat-obatan kunyit, jahe dan sereh serta ubi-ubian. Permukaan lahan didalam tapak masih berupa tanah dan sebagian besar area permukaan ditutupi oleh rumput. Jalanan disisi utara dan barat tapak menggunakan material aspal, disisi selatan masih berupa jalan setapak tanah, dan disebelah timu berbatasan dengan dinding-dinding rumah warga yang menggunakan material bata plaster, (Gambar 2).

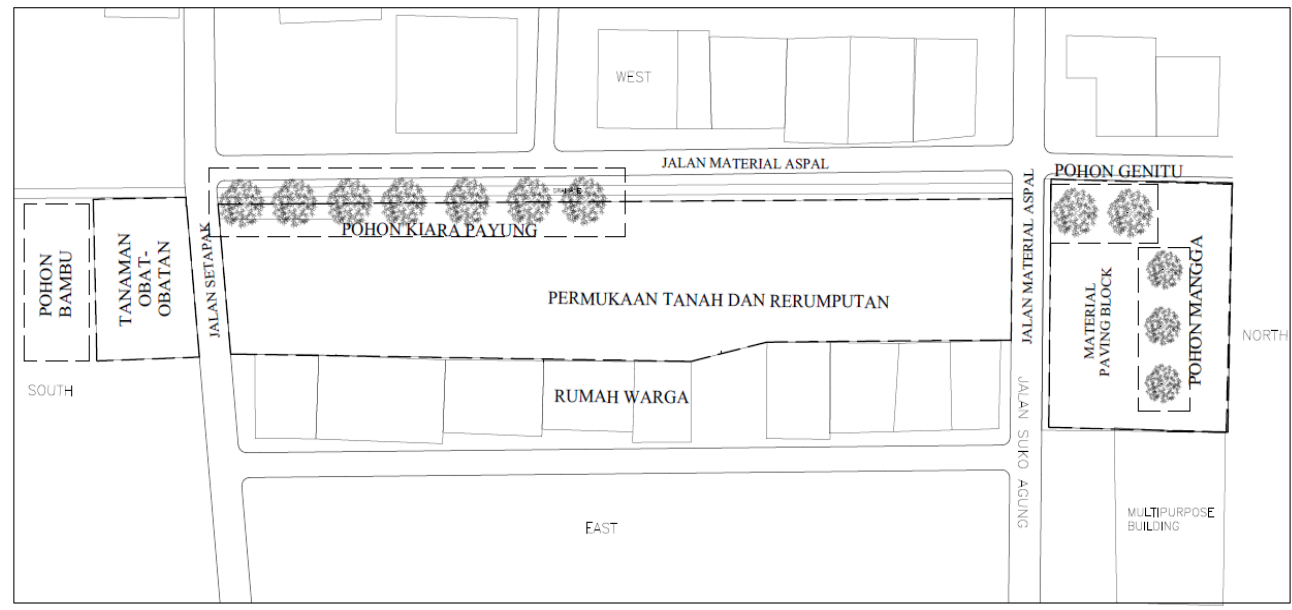

Gambar. 2

Kondisi vegetasi yang terdapat dalam tapak

Sumber: Hasil survei 2020

Pohon-pohon besar yang sudah ada pada eksisting perlu di pertahankan, dan juga perlu penambahan pepohonan didalam tapak. Area tanaman obat-obatan dan buah-buahan yang ada pada sisi selatan perlu di

PAWON: Jurnal Arsitektur, Nomor 01 Volume V, Bulan Januari-Juni Tahun 2021, ISSN 2597-7636 
tata ulang agar terlihat baik secara visual. Area vegetasi didalam tapak akan dilakukan pembersihan dan penataan ulang berdasarkan konsep tapak dan lanskap Taman Merah berdasarkan pemilihan material softscape dan hardscape yang ramah lingkungan dan berkelanjutan.

\subsection{Konsep Tapak}

Hasil identifikasi kriteria lanskap berkelanjutan dilingkungan warga Kampung Pelangi menunjukkan bahwa pendekatan lanskap berkelanjutan dapat digunakan untuk memberikan manfaat positif bagi warga Kampung Pelangi berdasarkan lima kriteria (Hamka, Winarni, \& Widhyarthara, 2020) sebagai berikut (Tabel 3):

Tabel 3.

Hasil identifikasi kriteria lanskap berkelanjutan di Kampung Pelangi

\begin{tabular}{|c|c|c|}
\hline No & Kriteria & Tujuan \\
\hline 1 & Lingkungan & $\begin{array}{l}\text { Untuk menjaga kualitas lingkungan dan ekosistemnya air, } \\
\text { tanah, udara, flora dan fauna }\end{array}$ \\
\hline 2 & Ekonomi & $\begin{array}{l}\text { Meningkatkan kemampuan ekonomi warga melalui } \\
\text { penanaman tanaman yang menghasilkan seperti buah- } \\
\text { buahan, ubi-ubian, dan obat-obatan sebagai bentuk } \\
\text { kemandirian dan ketahanan pangan yang dapat dikelolah dan } \\
\text { dimanfaatkan bersama-sama. Merancang taman untuk } \\
\text { peruntukan wisata ruang terbuka hijau, sehingga dapat } \\
\text { menarik pengunjung ke lingkungan Kampung Pelangi }\end{array}$ \\
\hline 3 & $\begin{array}{l}\text { Sosial } \\
\text { Budaya }\end{array}$ & $\begin{array}{l}\text { Dengan adanya rancangan taman merah maka akan } \\
\text { menambah pengetahuan warga melalui konsep lingkungan } \\
\text { yang diterapkan, meningkatkan Kesehatan warga, dan } \\
\text { sebagai sarana interaksi sosial budaya warga sekitar }\end{array}$ \\
\hline 4 & Arsitektural & $\begin{array}{l}\text { Diperlukan untuk memberikan pengalaman ruang dan tempat } \\
\text { yang menarik bagi pengunjung melalui penataan elemen- } \\
\text { elemen softscape dan hardscape taman }\end{array}$ \\
\hline 5 & Institusional & $\begin{array}{l}\text { Meningkatkan partisipasi dan kerjasama antar individu, } \\
\text { kelompok dan lembaga dalam membuat kebijakan untuk } \\
\text { mewujudkan konsep berkelanjutan di Taman Merah }\end{array}$ \\
\hline
\end{tabular}

Sumber: Hamka, Winarni, \& Widhyarthara, 2020

Kelima kriteria lanskap berkelanjutan diatas saling terkait dan memberikan dampak satu sama lain. Jika berangkat dari aspek ekonomi yaitu dengan pengembangan kawasan wisata taman ekologi, Kesehatan, kesenian, ruang komunal dan budidaya tanaman maka akan memberikan dampak langsung pada aspek lingkugan dan sosial budaya. Ketiganya membutuhkan dukungan dari aspek arsitektural dan institusional. Kerjasama dan dukungan semua pihak menjadi sangat penting untuk mewujudkan lingkungan yang dapat berpengaruh positif pada aspek ekonomi dan sosial budaya, namun tetap memiliki nilai estetika yang memberikan pengalaman 
ruang dan tempat menarik bagi pengunjung. Berikut ini gambaran hubungan antara konteks material softscape dan hardscape pada kriteria lanskap berkelanjutan di Taman Merah Kampung Pelangi RW 9 Kelurahan Merjosari Kota Malang, (Gambar 3).

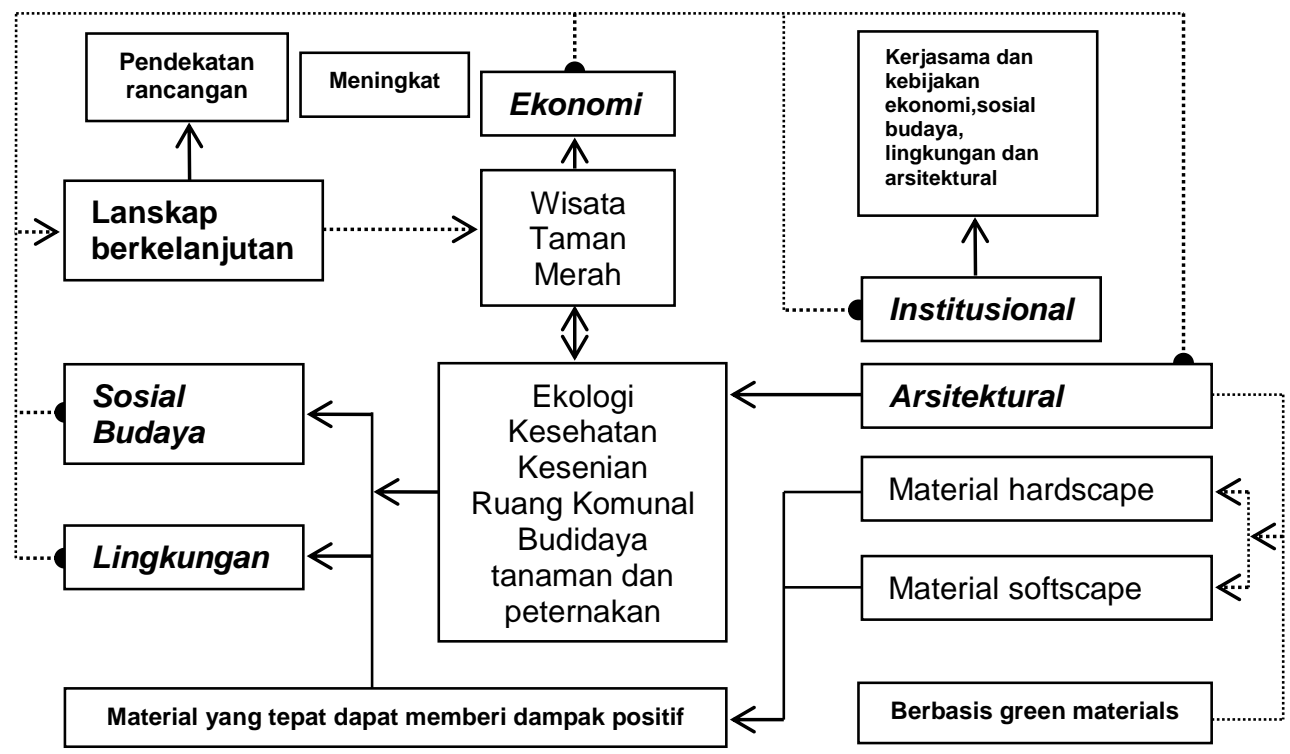

\section{Gambar. 3 \\ Skema hubungan timbal balik kriteria lanskap berkelanjutan Sumber: Hasil analisis 2020}

Rancangan taman sebagai fungsi ekologi, kesehatan, kesenian, ruang komunal, dan budidaya tanaman dan peternakan telah sesuai dengan karakter fisik dan non fisik masyarakat setempat. Berdasarkan pada hasil identifikasi kondisi lingkungan dan sosial masyarakat berikut ini daftar fasilitas yang akan diwadahi pada area Taman Merah Kampung Pelangi dan dibagi dalam 6 zona fungsi, yaitu: (1). Zona ekonomi terdiri dari lapak atau area warga dan pedagang kaki lima berjualan. (2). Zona pendukung public terdiri dari area terbuka umum yang dapat digunakan sebagai parkir kendaraan (3). Zona umum terdiri dari main entrance, plaza utama, sculpture, pendopo/ pangggung pagelaran, taman rembuk, dan taman sehat (4). Zona Pendidikan anak-anak, terdiri dari shelter perpustakaan, taman dongeng dan area bermain anak-anak, (5). Zona olahraga, tedapat lapangan multifungsi ang dapat digunakan sebagai lapangan bermain, lapangan futsal dan lapangan volley (6). Zona budidaya yang terdiri dari budidaya tanaman produktif (buah, sayuran, dan obat-obatan) dan budidaya peternakan ikan. 


\subsection{Kriteria Pemilihan Material}

Keenam zona fungsi yang terdapat pada Taman Merah perlu kajian pemilihan material softscape dan hardscape yang ramah lingkungan berdasarkan kriteria-kriteria literatur dan sejalan dengan pendekatan arsitektur berkelanjutan. Jika mengacu pada fungsi taman yang terdiri dari fungsi ekologi (memperbaiki kualitas air, tanah, udara,mencegah banjir dan meminimalisir polusi udara), fungsi sosial budaya (sebagai tempat rekreasi), fungsi arsitektural (kualitas visual dan kenyamanan kawasan), dan fungsi ekonomi (sarana wisata yang menumbuhkan lapangan pekerjaan) (Sulistyanto, 2014). Maka berikut ini kriteria pemilihan material hardscape dan softscape yang akan digunakan.

Kriteria softscape; Taman tidak menggunakan unsur air seperti air mancur dan sejenisnya agar mengurangi penggunaan daya listrik. Hanya disediakan kolam penampungan air hujan untuk kebutuhan budidaya tanaman dan peternakan ikan. Jenis tanaman yang ditanam diarea Taman Merah dibagi menjadi dua yaitu, jenis tanaman peneduh untuk fungsi ekologis (memperbaiki kualitas udara, penahan angin dan hujan serta sebagai tempat fauna liar). Jenis tanaman produktif seperti sayuran, tanaman obat-obatan, buah-buahan, yang juga sebagai fungsi ekologis (memperbaiki kualitas tanah) dan sekaligus fungsi ekonomi warga. Jenis tanaman hias yang berfungsi sebagai nilai estetik visual taman dengan mengutamakan pemilihan warna merah sebagai identitas karakter taman merah. Penggunaan sistem vertical garden dan tanaman merambat pada dinding dan atap.

Kriteria hardscape; menggunakan material yang ramah lingkungan, namun semaksimal mungkin mengurangi penggunaan permukaan keras untuk menjaga area resapan air tidak berkurang banyak. Permukaan tanah menggunakan kombinasi material keras dan lunak seperti rumput dan betonpada area terbuka, penggunaan batu koral agar air tetap bisa meresap, dan material pasir putih. Menggunakan material-material yang berwarna cerah sepertih putih, abu terang, hijau, dan merah karean warna cerah dapat mengurangi efek pantulan panas matahari. Efek panas dari pantulan sinar matahari akan dikurangi dengan pemilihan pohon peneduh yang dapat membayangi area ground cover berupa perkerasan. Penggunaan material keras tetap dapat dimanfaatkan pada bangunan, bangku taman, dan elemen pelengkap lainnya dengan material

\subsection{Material Softscape dan Hardscape Taman Merah}

Material softscape yang ada pada eksisting tapak perlu dipertahankan khususnya pohon-pohon besar. Namun untuk konsep zoning tapak yang ada, juga perlu penambahan pohon-pohon dengan fungsi peneduh pada sisi barat yang nanti dibawahya dapat difungsikan sebagai area bangku-bangku taman. Pada sisi timur juga ditambahkan pohon peneduh sekaligus 
berfungsi sebagai filter panas bagi dinding rumah warga yang berbatasan langsung dan juga berfungsi sebagai filter visual untuk menghalangi pandangan langsung menuju dinding rumah warga yang ada di sebelah timur tersebut. Pemilihan jenis pepohonan yang disebelah barat menyesuaikan dengan yang sudah ada yaitu pohon kiara agar tetap terlihat menyatu. Sedangkan untuk pepohonan yang berada disisi timur menggunakan pohon yang tidak miliki tajuk yang lebar seperti pohon pucuk merah dan Ketapang kencana. Pohon yang ada disisi timur dan barat ditanam berjajar mengikuti pedestrian dan sekaligus berfungsi sebagai pengarah. Selain itu juga perlu beberapa tanaman yang memiliki karakter unik pada bagian tengah tapak untuk memecah perhatian dan menjadi titik focus tapak seperti pohon angsana atau tabebuia. Berikut gambaran zoning tapak, sirkulasi dan titik pohon-pohon besar yang direncanakan dalam tapak, (Gambar 4).

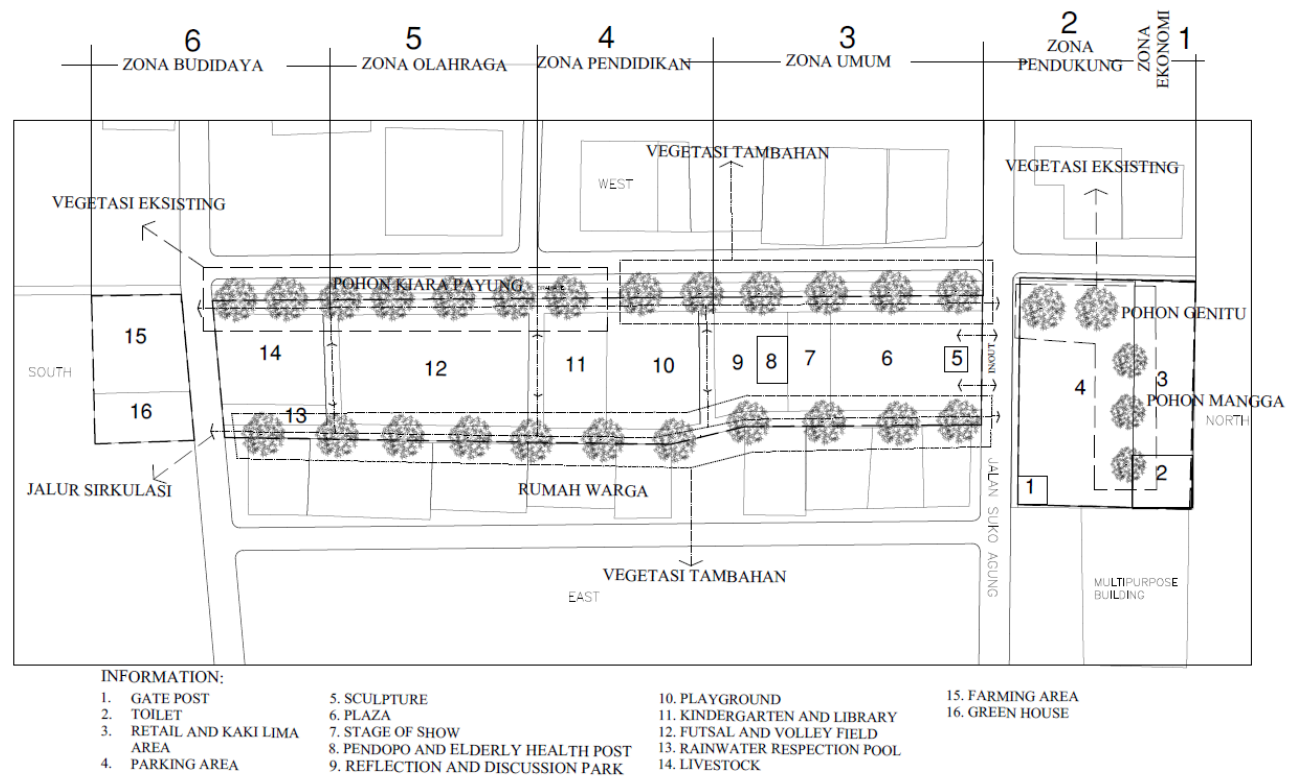

Gambar. 4

Zoning, sirkulasi, dan pepohonan tapak

Sumber: Hasil analisis 2020

\section{KESIMPULAN}

Berdasarkan pada hasil pembahasan dan kriteria yang ditentukan maka material softscape yang digunakan adalah dibagi menjadi tiga yaitu tanaman untuk fungsi ekologi, fungsi estetika dan fungsi ekonomi atau ketahanan pangan berupa tanaman produktif seperti buah-buahan, sayur dab obat-obatan. Material hardscape diselesaikan dengan cara mengurangi penggunaan perkerasan secara keseluruhan, misalkan kombinasi antara beton dan rumput, krikil atau batu koral, penggunaan pasir putih untuk 
lapangan futsal dan volley. Hal tersebut bertujuan agar area resapan air pada taman tetap terjaga. Tetap mempertahankan vegetasi eksisiting yang ada didalam tapak, sehingga tidak merusak kondisi ekosistem tapak.

\section{DAFTAR PUSTAKA}

Ashihara, Y., 1996. Perancangan Eksterior dalam Arsitektur. Abdi Widya:Bandung.

Çiftçioğlu and Sözen. 2017. "Towards Sustainable Landscape Development Indicators for North Cyprus". TÜBAV Bilim 10 (1) 2. 75-85.

Hakim, R. (2000). Komponen Perancangan Arsitektur Lanskap. Jakarta: Bumi Aksara

Hamka, Winarni, \& Widhyarthara, 2020. Study of Sustainable Landscape Criteria in Order to Green Open Space Planning for Settlements in RW 9Kelurahan Merjosari -Malang. ESE INTERNATIONAL JOURNAL (Environmental Science and Engineering) ISSN. 2622- 3228 Volume 3 Issue.1 Pages: 13-22

Handayani, 2009. Arsitektur Lanskap. Modul Kuliah Arsitektur UPI, Jakarta.

Pratiwi \& Safitri, 2019. Upaya Mengurangi Urban Heat Island Melalui Pemilihan Material (Studi Kasus: RPTRA Meruya Selatan). Jurnal Abdi Masyarakat Indonesia Volume 1 No. 2, Hal. 42-47

Simond, J.O. (2006). Landscape Architecture. USA: 3rd edition. Mc Graw Hill Inc.

Surjana \& Ardiansyah, 2013. Perancangan Arsitektur Ramah lingkungan: Pencapaian Rating Greenship GBCl. Jurnal Arsitektur UniversitasJAU, Bandar Lampung. No.3 Vol.2, Hal. 1-14

Susanti, A. 2000. Pedoman Pengembangan Objek Wisata Agro, Gramedia. Jakarta

Sulistyantara, B. 2002. Taman Rumah Tinggal. PT Penebar Swadaya. Jakarta.

Sulistyanto, 2014. "Penataan Ruang Terbuka Hijau (RTH) pada Kawasan Rumah Pemotongan Hewan (RPH) Samarinda". Jurnal Teknik Sipil dan Arsitektur. Universitas Tunas Pembangunan Surakarta. Vol 15, No 19.

Wahyuni \& Qomarun, 2013. Identifikasi Lansekap Elemen Softscape dan Hardscape pada Taman Balekambang Solo. Sinektika Vol.13 No.2, Hal. 114-124 